\title{
Red Palm Oil Attenuates Lead Acetate Induced Testicular Damage in Adult Male Sprague-Dawley Rats
}

\author{
A. I. Jegede, ${ }^{1,2}$ U. Offor, ${ }^{1}$ O. O. Azu, ${ }^{1}$ and O. Akinloye ${ }^{3}$ \\ ${ }^{1}$ Discipline Clinical Anatomy, School of Laboratory Medicine and Medical Sciences, Nelson R Mandela School of Medicine, \\ University of KwaZulu-Natal, Durban 4013, South Africa \\ ${ }^{2}$ Anatomy Department, Faculty of Basic Medical Sciences, College of Health Sciences, Ladoke Akintola University of Technology, \\ Ogbomoso, Oyo State 210001, Nigeria \\ ${ }^{3}$ Department of Medical Laboratory Science, Faculty of Basic Medical Sciences, College of Medicine, \\ University of Lagos, Lagos 100001, Nigeria
}

Correspondence should be addressed to O. Akinloye; oluyemiakinloye@hotmail.com

Received 11 March 2015; Accepted 2 September 2015

Academic Editor: Vincenzo De Feo

Copyright (C) 2015 A. I. Jegede et al. This is an open access article distributed under the Creative Commons Attribution License, which permits unrestricted use, distribution, and reproduction in any medium, provided the original work is properly cited.

\begin{abstract}
To study the protective effect of Red Palm Oil (RPO) on testicular damage induced by administration of lead acetate on male Sprague-Dawley rats, 28 rats divided into four groups of 7 animals each were used. They were administered orally with RPO $(1 \mathrm{~mL}$ and $2 \mathrm{~mL}$ ) and lead acetate (i.p.) $6 \mathrm{mg} / \mathrm{kg}$ body weight/day, respectively. Treatment was conducted for 8 weeks, and $24 \mathrm{hrs}$ after the last treatment the rats were sacrificed using cervical dislocation. Sperms collected from epididymis were used for seminal fluid analyses; while the testes sample was used for ROS and oxidative enzyme activities assessment. Statistical analysis was carried out using GraphPad Prism 5.02 statistical analysis package. Administration of lead acetate increased generation of reactive oxygen species (ROS) significantly $(p<0.05)$ as evidenced by the elevated value of $\mathrm{H}_{2} \mathrm{O}_{2}$ and LPO and decreased GSH level. Also there was reduced epididymal sperm count, poor grade of sperm motility, and lower percentage of normal sperm morphology significantly. Coadministration with RPO, however, has a protective effect against lead toxicity by decreasing $\mathrm{H}_{2} \mathrm{O}_{2}$ production, increased GSH level, and increased sperm qualities especially. This shows that RPO has a potential to attenuate the toxic effect of lead on testicular cells preventing possible resultant male infertility.
\end{abstract}

\section{Introduction}

Red palm oil (RPO) is produced from the fruit of the oil palm tree (Elaeis guineensis). It originated from tropical Africa and now spread to most part of the world. RPO is an important produce from oil palm in Southeast Asia, West Africa, and South America [1]. Throughout history RPO has served as the primary source of dietary fat. Its nutritional and healing properties have been recognized for generations. Until modern medicine arrived, RPO was the remedy of choice for several illnesses in many parts of Africa. RPO is regarded among many as essential in the diet for pregnant and nursing mothers in order to ascertain good health of the mother and child [2]. RPO is virtually regarded as powerhouse of nutrition containing by far more nutrients than any other dietary oil [3]. In addition to beta-carotene, alpha-carotene, and lycopene it contains at least 20 other carotenes along with vitamin $\mathrm{E}$, vitamin $\mathrm{K}, \mathrm{CoQ} 10$, squalene, phytosterols, flavonoids, phenolic acids, and glycolipids. RPO is one of the richest natural sources of vitamin $\mathrm{E}$. In addition to ordinary vitamin $\mathrm{E}$, it also contains the highest amount of a super potent form of vitamin $\mathrm{E}$ known as tocotrienol. There are four tocotrienols, which are all present in RPO. These tocotrienols have up to 60 times the antioxidant activity of ordinary vitamin E. The combination of vitamin E, tocotrienols, carotenes, and other antioxidants makes palm oil a super antioxidant food $[3,4]$. RPO is the only vegetable oil with a balanced composition of saturated and unsaturated fatty acids in both processed and unprocessed forms [5]. It contains carotenoids, phosphatides, sterols, tocopherols, and trace metals [5], shown to be effective against oxidative stress in vitro and in vivo [6]. It has also been shown that RPO 
exerted effects on reproductive capacity by improving the efficiency of protein biosynthesis or utilization in such a way that was favorable to sex hormone function in rats fed with $\mathrm{RPO}[7,8]$. It is also likely that RPO provide vitamin A, which is known to play a part in reproduction through the synthesis of sex steroids [7], embryogenesis, and spermatogenesis [9].

Lead is a toxic heavy metal that can damage nervous connections (especially in young children) and cause blood and brain disorders. Lead poisoning typically results from ingestion of food or water contaminated with lead but may also occur after accidental ingestion of contaminated soil, dust, or lead based paint [10]. Long-term exposure to lead or its salts (especially soluble salts or the strong oxidant $\mathrm{PbO}_{2}$ ) can cause nephropathy and colic-like abdominal pains. Concentrations of blood lead $>40 \mu \mathrm{g} / \mathrm{dL}$ seem to be associated with a decrease in sperm count, sperm volume, sperm motility, and morphological alterations [11, 12]. Chronic, high-level exposure has shown to reduce fertility in male [13]. The effects of lead are the same whether it enters the body through breathing or swallowing. Lead is probably toxic to most organs and systems in the body. Chronic lead poisoning is commonly seen in young children from sucking lead paint or lead toys and in workers engaged in printing, paint, and petroleum industries [14]. Reproductive dysfunction by lead has distinct morphological and biochemical features such as disorganized epithelia, decreased sperm quality and altered sperm morphology, and low androgen levels $[12,15,16]$. In the animal model, lead has a primary toxic effect on the hypothalamic pituitary unit and a primary effect on the testes and acts at all levels of the reproductive axis [17].

Industrial lead exposure is rampant among people working in some industries such as paint and battery making companies. Leaded gasoline is still in use in many developing countries resulting in environmental lead pollution. The incidence of lead poison around the world remains unabated as recent cases are still reported in countries like Nigeria, China, and Japan $[10-13,16]$. This calls for scientific research to find out substances especially natural products that could prevent or reduce lead toxicity in high risk population. This study was designed specifically to attenuate lead induced testicular damage.

\section{Materials and Methods}

2.1. Source of Chemicals. Red palm oil from Linkjon commercial processing oil mill, certified after quality indices were determined for moisture content, free fatty acid (FFA), acid value, and saponification value using standard methods by National Agency for Food and Drug Administration and Control (NAFDAC), was purchased from Sabo oil market in Ilesa, Osun State. Nigeria and all other chemicals were purchased from Sigma Chemicals, USA. The administered dose of lead acetate was selected according to our previous study [16].

2.2. Animals. Twenty-eight healthy adult male SpragueDawley rats (10 weeks old, $165 \mathrm{~g}$ average body weight) were housed in clean polypropylene cages and maintained in animal housing facility with constant $12 \mathrm{~h} / 12 \mathrm{~h}$ dark and light cycle. All animal handling procedure was approved by the College Ethics Committee.

2.3. Experimental Protocol. The rats were divided into four groups $(n=7)$, labeled as groups I, II, III, and IV. Group I represents control and received water as placebo. Group II was administered (i.p.) with $6 \mathrm{mg} / \mathrm{kgbw}$ lead acetate only. Groups III and IV intraperitoneally received $6 \mathrm{mg} / \mathrm{kgbw}$ of lead acetate and 1 and $2 \mathrm{~mL}$ of RPO, respectively. Feed and water were made available ad libitum.

The administration lasted for 8 weeks. Lead acetate was administered intraperitoneally and palm oil was administered orally with the use of oral cannula. Twenty-four hours after the last treatment, the animals were sacrificed by cervical dislocation after which the testes and epididymis were removed for sperm assessment and all left testes were fixed in Bouin's fluid and epididymis in normal saline while all the right testes were stored at $-80^{\circ} \mathrm{C}$ until analysis. Also the initial and final body weights of the rats were taken before the commencement of treatment and prior to sacrifice.

2.4. Seminal Fluid Analyses. The sperm count was done using new improved Neubauer's hemocytometer (Deep 1/10 mm, LABART, Germany). This procedure including evaluation of sperm motility and morphology was done as reported in our previous study [16].

2.5. Antioxidant Enzyme. Samples from testes were homogenized in $50 \mathrm{mM}$ tris-HCL buffer (pH7.4) containing 1.15\% potassium chloride and the homogenate cold $\left(4^{\circ} \mathrm{C}\right)$ centrifuged at $10,000 \times \mathrm{g}$ for 15 minutes. The supernatant was collected for the estimation of markers of oxidative stress; $\mathrm{H}_{2} \mathrm{O}_{2}$, LPO, and GSH levels were assayed as described by Adedara and Farombi, 2014 [18, 19].

2.6. Histological Procedure. Tissues were fixed in Bouin's fluid for routine $\mathrm{H} \& \mathrm{E}$ histological preparation and photomicrographs of the sections were taken at different magnifications.

2.7. Statistical Analysis. The results were statistically analyzed using the Prism 5 for Windows (version 5.02, GraphPad Software, Inc.). The Mean \pm Standard Error of Means of the data was calculated. One-way ANOVA was used to check the significance differences within and between groups while Student's $t$-test was used to compare difference between means. The difference of means was considered significant at $p<0.05$.

\section{Results}

Mortality. No mortality was recorded during the course of the experiment.

3.1. Body Weight. The body weight of animals in groups II and III was reduced compared to controls $(p<0.05)$ with $15.2 \%$ and $11.05 \%$ decrease in body weight, respectively, while 


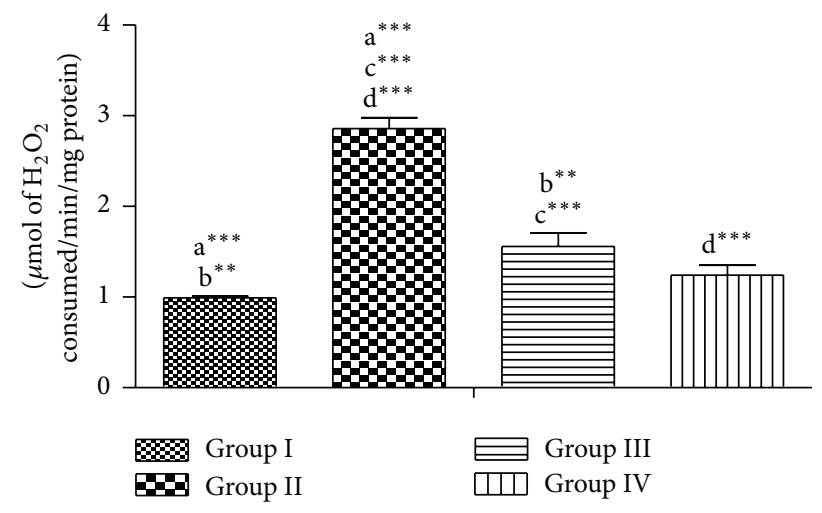

FIGURE 1: Effect of RPO on the $\mathrm{H}_{2} \mathrm{O}_{2}$ level in testes of rat treated with lead acetate. Each bar represents the mean \pm SEM of 7 rats.

the final body weight of group IV animals increased by $14.28 \%$ (Table 1).

3.2. Seminal Fluid Analyses. The sperm count of all the lead acetate groups was significantly reduced when compared to group I. Group II records a more overtly low sperm count which is significant compared to all other groups; however, there is no significant difference in sperm count between groups III and IV (Table 1). Sperm motility grading showed that there is a high cell death and reduced motility in group II compared to the control group and the groups that receive RPO treatment where 64\% (group III) and 66\% (group IV) rapid progressive motility were recorded against $26 \%$ recorded in group II (Table 1).

3.3. Testicular Oxidative Stress Status. Lead acetate significantly increased the levels of $\mathrm{H}_{2} \mathrm{O}_{2}$ and LPO and reduced the level of GSH (group II), while it is seen in groups III and IV that were coadministered with RPO that there are no significant changes in the enzymes activities when compared to group I, meaning that the testes were protected from lead which induces oxidative stress (Figures 1,2, and 3).

3.4. Histology. Figures 4-7 represent histological changes of testes in each group at two magnifications.

\section{Discussion}

Heavy metals are widely distributed in the environment. Environmental discharge of lead due to the use of petroleum products (especially leaded petrol), construction works, paint removal, demolition, vehicle batteries, and car repairs contribute to airborne lead pollution [20] and possibly introduce high concentrations of this potential reproductive toxicant into the environment, which may cause physiological, biological, and histological disorders [16, 21, 22]. Finding protection for these exposed individual becomes highly necessary. The present study highlights various deleterious impacts of lead acetate on the testicular parameters. We observed a statistically significant $(p<0.05)$ declined body weight $(15.2 \%)$ in lead acetate only treated groups when compared to the

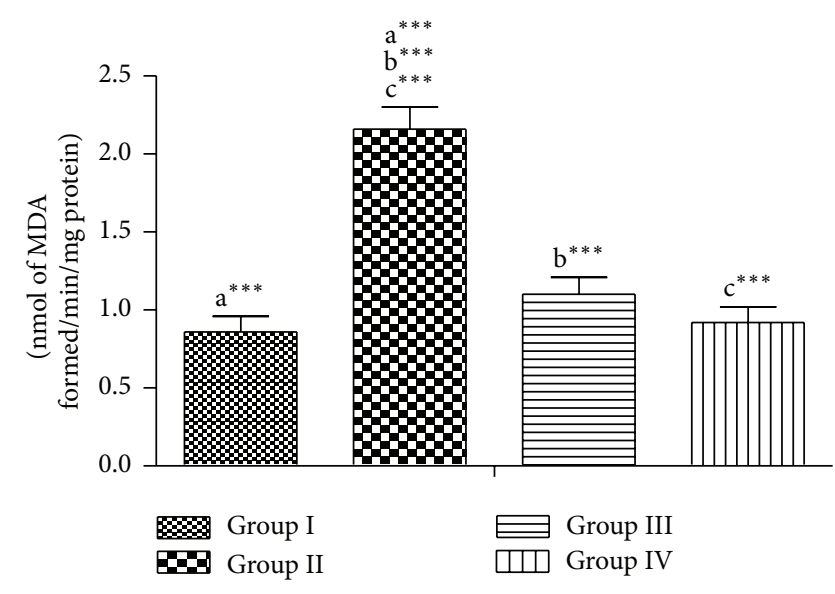

FIGURE 2: Effect of RPO on the LPO level in testes of rat treated with lead acetate. Each bar represents the mean \pm SEM of 7 rats.

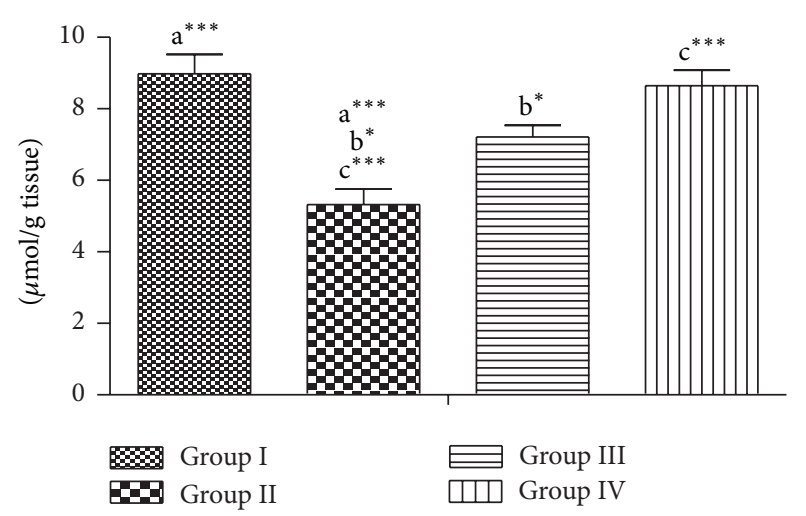

FIGURE 3: Effect of RPO on the GSH activity in testes of rat treated with lead acetate. Each bar represents the mean \pm SEM of 7 rats.

control. Also weight loss of $11.05 \%$ was recorded in group treated with $1 \mathrm{~mL}$ of RPO against a weight gain of $14.28 \%$ in group treated with $2 \mathrm{~mL}$ RPO. RPO attenuated the weight loss in lead treated animals in doses dependent manner. The higher the doses of palm oil, the lesser the weight lost. Although the observed initial animal body weight range for the experiment is wide, this did not in any way significantly influenced the change observed. Whereas increased food consumption by the animals in RPO (higher dose group) is plausible, the overall effects of these changes are statistically factored in the design of the experiment.

The seminal fluid assessments (sperm count and sperm motility) were significantly decreased in the lead treated groups (II, III, and IV) compared with group I; this shows that lead toxicity causes oligospermia. Similar observations were recorded in experimental animal experimental models exposed to heavy metals $[16,21,23,24]$. However, a slight increase was noticed in the groups treated with RPO in a dose dependent manner. This agrees with previous report that palm oil is a potential supplement to increased fertility [25]. The significant high level of dead sperm cells in group I shows that lead has adverse inhibitory effect on the postmeiotic cells, 
TABLE 1: The Mean \pm SEM of body weights of the rats and \% body weight difference of the groups and seminal fluid analyses parameters.

\begin{tabular}{|c|c|c|c|c|}
\hline & Group I & Group II & Group III & Group IV \\
\hline \multicolumn{5}{|l|}{ Body weight (g) } \\
\hline Initial weight & $204.38 \pm 5.74$ & $121.80 \pm 8.14$ & $151.70 \pm 3.82$ & $118.90 \pm 7.07$ \\
\hline Final weight & $210.50 \pm 5.46$ & $103.20 \pm 7.55$ & $134.94 \pm 4.08$ & $138.70 \pm 6.78$ \\
\hline Weight difference (\%) & $+6.12(2.99)^{\mathrm{abc}}$ & $-18.60(15.2)^{\mathrm{a}}$ & $-16.76(11.05)^{\mathrm{b}}$ & $+19.80(14.28)^{\mathrm{c}}$ \\
\hline Sperm count $\left(\times 10^{6}\right)$ & $78.00 \pm 7.8^{\mathrm{abc}}$ & $15.70 \pm 7.4^{\text {ade }}$ & $32.30 \pm 3.3^{\mathrm{bd}}$ & $34.90 \pm 4.2^{\mathrm{ce}}$ \\
\hline \multicolumn{5}{|l|}{ Motility grading (\%) } \\
\hline Rapid progressive & $84.0 \pm 1.0^{\mathrm{abc}}$ & $26.0 \pm 7.75^{\mathrm{acd}}$ & $64.0 \pm 5.10^{\mathrm{bc}}$ & $66.0 \pm 6.78^{\mathrm{cd}}$ \\
\hline Slow progressive & $8.0 \pm 2.0^{\mathrm{abc}}$ & $12.0 \pm 2.0^{\mathrm{a}}$ & $16.0 \pm 4.0^{\mathrm{b}}$ & $22.0 \pm 3.7^{\mathrm{c}}$ \\
\hline Nonprogressive & $5.0 \pm 0.0^{\mathrm{a}}$ & $27.0 \pm 5.8^{\mathrm{abc}}$ & $11.0 \pm 3.8^{\mathrm{b}}$ & $7.0 \pm 1.2^{\mathrm{c}}$ \\
\hline Dead & $5.0 \pm 0.0^{\mathrm{a}}$ & $32.0 \pm 3.2^{\mathrm{abc}}$ & $7.0 \pm 5.8^{\mathrm{b}}$ & $5.0 \pm 0.0^{c}$ \\
\hline \multicolumn{5}{|l|}{ Morphology assessment (\%) } \\
\hline Normal & $79.0 \pm 2.92^{\mathrm{abc}}$ & $40.0 \pm 7.07^{\mathrm{ad}}$ & $46.0 \pm 2.45^{\mathrm{b}}$ & $52.0 \pm 3.74^{\mathrm{cd}}$ \\
\hline Head defect & $10.0 \pm 2.24^{\mathrm{abc}}$ & $42.0 \pm 2.00^{\mathrm{a}}$ & $40.0 \pm 3.16^{\mathrm{b}}$ & $38.0 \pm 3.73^{c}$ \\
\hline Tail defect & $6.0 \pm 1.00$ & $7.0 \pm 1.23$ & $6.0 \pm 1.00$ & $5.0 \pm 0.0$ \\
\hline Middle piece defect & $5.0 \pm 1.0^{\mathrm{a}}$ & $11.0 \pm 5.15^{\mathrm{a}}$ & $6.0 \pm 0.0$ & $5.0 \pm 1.0$ \\
\hline
\end{tabular}

Values with the same superscripts on the same row are statistically significant at $p$ value $<0.05(n=7)$.
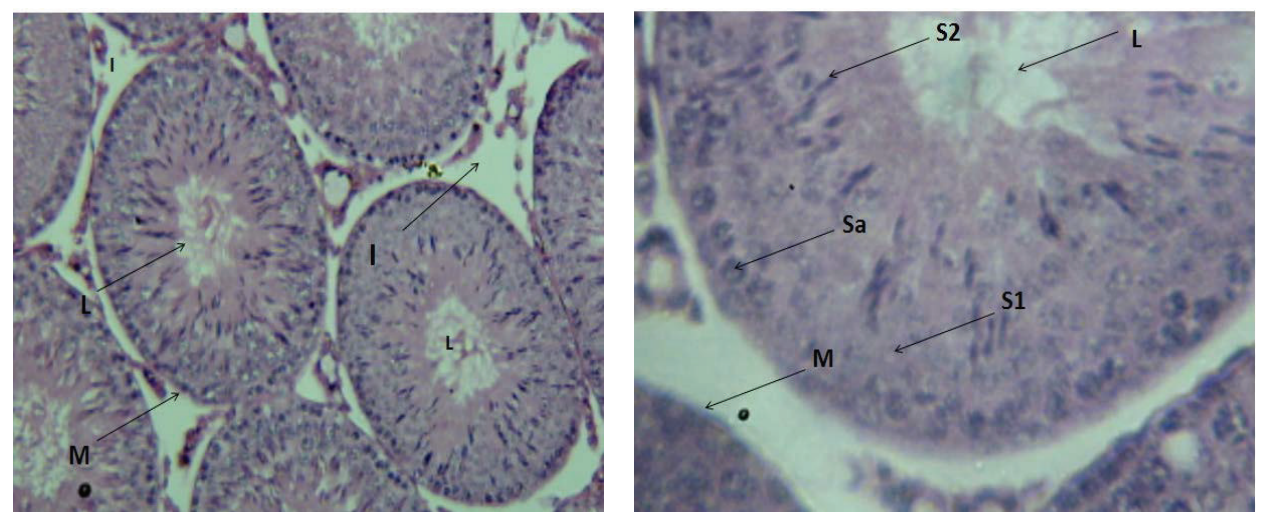

Figure 4: Cross section of the testis of rat in group I $(\mathrm{H} \& \mathrm{E}, \times 100$ and $\times 400$, resp. $)$. Lumen $=\mathrm{L}$, basement membrane $=\mathrm{M}$, interstitial space $=$ $\mathrm{I}$, spermatogonia $=\mathrm{Sa}$, primary spermatocytes $=\mathrm{S} 1$, and spermatids $=\mathrm{S} 2$.
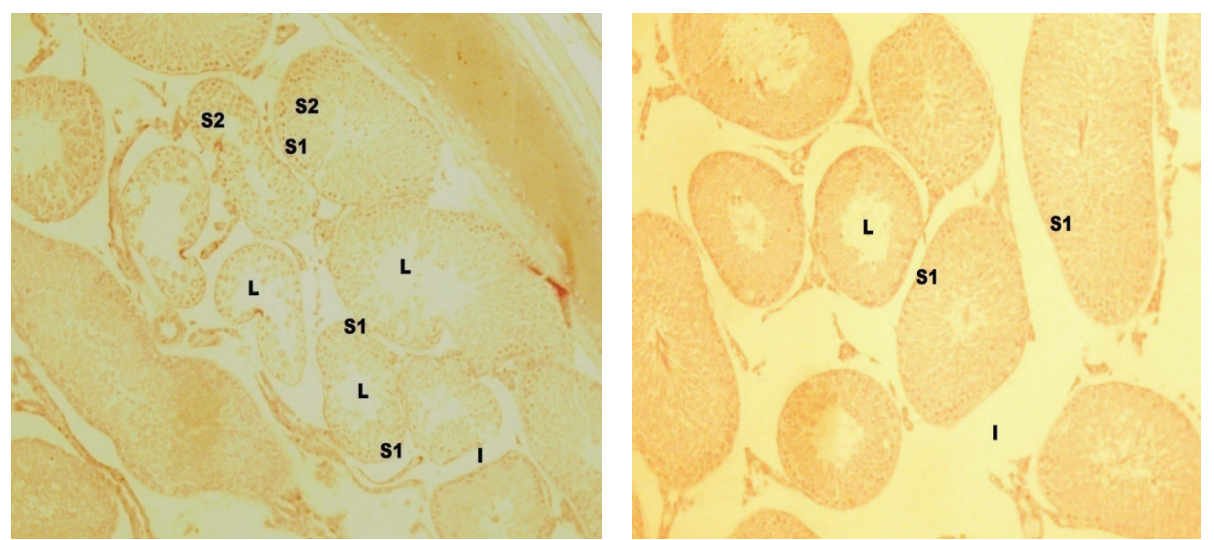

FIgURE 5: Cross section of the testis of rat in group II $(\mathrm{H} \& \mathrm{E}, \times 40, \times 100)$. S1 $=$ spermatogonia cells, $\mathrm{L}=$ lumen, and $\mathrm{I}=$ interstitial spaces. 

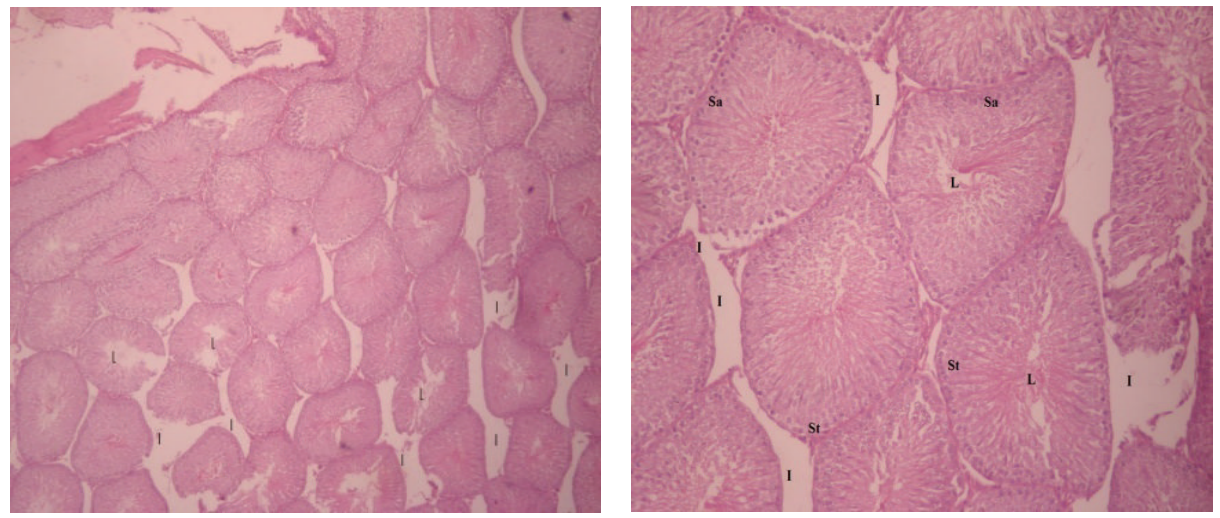

Figure 6: Cross section of group III (H\&E, $\times 40, \times 100$, resp.). $\mathrm{L}=$ lumen, $\mathrm{I}=$ interstitial cells, $\mathrm{Sa}=$ spermatogonia, and St $=$ primary spermatocyte.
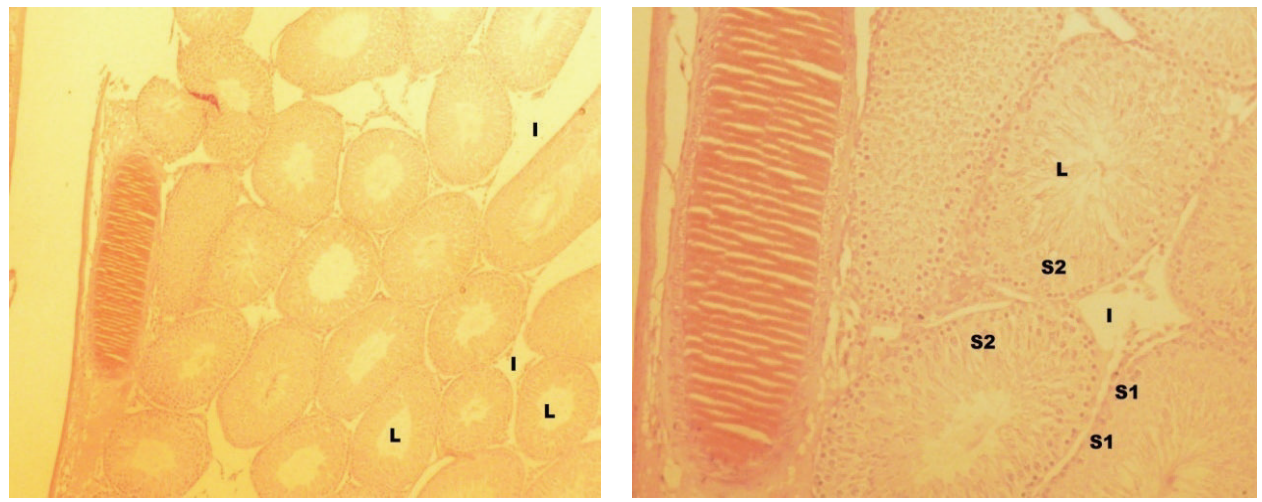

FIGURE 7: Cross section of group IV (H\&E, $\times 40, \times 100$, resp.). $\mathrm{L}=$ lumen, $\mathrm{I}=$ interstitial space, and $\mathrm{S} 2=$ seminiferous tubule.

mainly pachytene spermatocyte and Leydig cell as seen in the complete erosion of the interstitial cell.

The percentage of the sperms with normal morphology in lead treated groups (groups II, III, and IV) was decreased with high prevalence of sperm head abnormality compared with control; this concurs with the earlier report which indicated that lead altered testis histology resulting in structural defects in sperms [26]. Also, the percentage of sperms with normal morphology was significantly increased in group II compared to group I; this is probably due to the protective effect of palm oil. The testicular histopathological evaluation of our result showed that lead produced germ cell apoptosis, spermatogenic arrest, testicular atrophy, and generalized degeneration of the interstitial space (Figures 5-7). It was seen that spermatogonia cells were the only features seen in group II; this implies that there is an arrest of the sperm development as no fully matured cell can be seen which implies that the process of spermatogenesis is affected by lead. This result agreed with the report of Al-Azemi et al. [27] where administration of $\mathrm{Cd}$, another heavy metal, was shown to be spermatogenic state specific.

Reactive oxygen species (ROS) are highly reactive forms of oxygen, free radicals (FR), which are short-lived intermediate containing one or more unpaired electrons. They include an array that has superoxide anion $\left(\mathrm{O}^{2-}\right)$, hydrogen peroxide $\left(\mathrm{H}_{2} \mathrm{O}_{2}\right)$, hydroxyl radical $(\mathrm{OH})$, nitric oxide $(\mathrm{NO})$, hypochlorous acid $(\mathrm{ClOH})$, peroxide $(\mathrm{ROOH})$, and peroxynitrite (ONOO) [28]. These highly reactive species are generated in a number of conditions by cellular and acellular mechanism and have been implicated as an aetiological factor of a wide range of diseases. Studies have indicated that heavy metals act as catalysts in the oxidative reactions in biological reactions and that toxicity of these heavy metals may be due to oxidative tissue damage $[21,29]$. The result of assay of level of $\mathrm{H}_{2} \mathrm{O}_{2}$ and LPO in this study shows a significant increase in the amount of generation of these free radicals in the lead acetate only treated group and a similar decrease in the RPO administered groups in a dose dependent manner. GSH is an intercellular antioxidant which is usually in high concentration within cell. In mice treated with heavy metals there were significant decreases in the levels of GSH and SOD in kidney and testicular tissues [21]; our result followed this similar pattern of low level of GSH in the lead acetate exposed groups. There was a high significant reduction in the GSH in group II compared to control group I (Figure 3). This marked low level of GSH is due to the excessive utilization of the antioxidant in scavenging for the high amount of free radicals produced by lead acetate. But this effect was reversed to a near normal state in group IV, where RPO was seen to alleviate the generation of free radicals by protecting 
the testicular tissue and hence a significant increase in the level of GSH. It can therefore be postulated that the protective action of RPO is similar to the role of intracellular GSH which is the most important protective mechanism for free radical scavenging and inhibitor of electrophilic xenobiotics attack on cellular macromolecules [30]. Preventative antioxidants, such as metal chelators and metal binding proteins, block the formation of new ROS, whereas scavenger antioxidants such as vitamins $\mathrm{E}$ and $\mathrm{C}$, beta-carotene, and other antioxidants dietary supplements, glutathione and enzymes, remove ROS already generated by cellular oxidation. Dietary products such as vitamins $\mathrm{C}, \mathrm{E}$, and A are some of the excellent sources of antioxidant [31] and RPO is a virtual powerhouse of nutrition. It contains, by far, more nutrients than any other dietary oil. A new dimension to the view above from our study is to consider ranking RPO in the group of preventive antioxidants, since it appears to block the formation of ROS.

\section{Conclusion}

Our results suggest that RPO offers positive protection against lead acetate induced testicular injuries. However, further studies are warranted to elaborate on the definite mechanism of its antioxidative potential.

\section{Conflict of Interests}

The authors declare that there is no conflict of interests regarding the publication of this paper.

\section{References}

[1] A. J. Esterhuyse, E. F. Du Toit, and J. Van Rooyen, "Dietary red palm oil supplementation protects against the consequences of global ischemia in the isolated perfused rat heart," Asia Pacific Journal of Clinical Nutrition, vol. 14, no. 4, pp. 340-347, 2005.

[2] S. Khanna, S. Roy, H. Ryu et al., "Molecular basis of vitamin E action: tocotrienol modulates 12-lipoxygenase, a key mediator of glutamate-induced neurodegeneration," The Journal of Biological Chemistry, vol. 278, no. 44, pp. 43508-43515, 2003.

[3] A. C. Tomeo, M. Geller, T. R. Watkins, A. Gapor, and M. L. Bierenbaum, "Antioxidant effects of tocotrienols in patients with hyperlipidemia and carotid stenosis," Lipids, vol. 30, no. 12, pp. 1179-1183, 1995.

[4] S. H. Goh, T. P. Loh, J. M. Huang, Y. M. Choo, and N. F. Hew, "Antioxidants in palm oil: their chemistry and some insights from feeding experiments on rabbits," in Biological Oxidants and Antioxidants: Molecular Mechanisms and Health Effects, A. S. H. Ong and L. Packer, Eds., pp. 274-283, American Oil Chemists Society, Champaign, Ill, USA, 2012.

[5] K. Sundram, R. Sambanthamurthi, and Y.-A. Tan, "Palm fruit chemistry and nutrition," Asia Pacific Journal of Clinical Nutrition, vol. 12, no. 3, pp. 355-362, 2003.

[6] E. Serbinova, M. Choo, and L. Packer, "Distribution and antioxidant activity of a palm oil carotene fraction in rats," Biochemistry International, vol. 28, no. 5, pp. 881-886, 1992.

[7] C. Alais and G. Linden, Food Biochemistry, Aspen Publisher, Frederick, Md, USA, 1st edition, 1999.

[8] Y. G. Aboua, N. Brooks, R. Z. Mahfouz, A. Agarwal, and S. S. du Plessis, "A red palm oil diet can reduce the effects of oxidative stress on rat spermatozoa," Andrologia, vol. 44, no. 1, pp. 32-40, 2012.

[9] H. J. McArdle and C. J. Ashworth, "Micronutrients in fetal growth and development," British Medical Bulletin, vol. 55, no. 3, pp. 499-510, 1999.

[10] Toxicological profile for lead, Public Health Service Agency for Toxic Substances and Disease Registry, 2007, http://www .atsdr.cdc.gov/toxprofiles/tp13.pdf.

[11] L. D. Grant, "Lead and compounds", in Environmental Toxicants: Human Exposure and Their Health Effect, M. Lippmann, Ed., Wiley-Interscience, New York, NY, USA, 3rd edition, 2009.

[12] P.-C. Hsu, C.-C. Hsu, M.-Y. Liu, L.-Y. Chen, and Y. L. Guo, "Lead-induced changes in spermatozoa function and metabolism," Journal of Toxicology and Environmental Health A, vol. 55, no. 1, pp. 45-64, 1998.

[13] S. G. Mari, "Summary," in Metals, Fertility, and Reproductive Toxicity, p. 153, Taylor \& Francis Group, Boca Raton, Fla, USA, 2005, http://books.google.com/?id=Qt8LEB7_ HyQC\&pg=PA153.

[14] R. S. Satoskar, S. D. Bhandarkar, and S. S. Alnapure, Pharmacology and Pharmacotherapeutics, Prakashan, Mumbai, India, 6th edition, 1999.

[15] P.-C. Hsu, M.-Y. Liu, C.-C. Hsu, L.-Y. Chen, and Y. L. Guo, "Lead exposure causes generation of reactive oxygen species and functional impairment in rat sperm," Toxicology, vol. 122, no. 1-2, pp. 133-143, 1997.

[16] A. I. Jegede, M. B. Ajadi, and O. Akinloye, "Modulatory effects of Kolaviron (Garcina kola extract) on spermogram and reproductive system of adult male Wistar rats in lead acetate induced toxicity," Journal of Toxicology and Environmental Health Sciences, vol. 5, no. 7, pp. 121-130, 2013.

[17] R. Z. Sokol, "Hormonal effects of lead acetate in the male rat: mechanism of action," Biology of Reproduction, vol. 37, no. 5, pp. 1135-1138, 1987.

[18] I. A. Adedara and E. O. Farombi, "Kolaviron protects against ethylene glycol monoethyl ether-induced toxicity in boar spermatozoa," Andrologia, vol. 46, no. 4, pp. 399-407, 2014.

[19] L. Devi, V. Raghavendran, B. M. Prabhu, N. G. Avadhani, and H. K. Anandatheerthavarada, "Mitochondrial import and accumulation of $\alpha$-synuclein impair complex I in human dopaminergic neuronal cultures and Parkinson disease brain," Journal of Biological Chemistry, vol. 283, no. 14, pp. 9089-9100, 2008.

[20] A. Pizent, B. Taribe, and T. Zivkovic, "Reproductive toxicity of metals in men," Arhiv za Higijenu Rada i Toksikologiju, vol. 63, supplement 1, pp. 35-46, 2012.

[21] A. M. Al-Attar, "Antioxidant effect of vitamin E treatment on some heavy metals-induced renal and testicular injuries in male mice," Saudi Journal of Biological Sciences, vol. 18, no. 1, pp. 6372, 2011.

[22] A. T. Philip and B. Gerson, "Lead poisoning-part I. Incidence, etiology, and toxicokinetics," Clinics in Laboratory Medicine, vol. 14, no. 2, pp. 423-444, 1994.

[23] O. Akinloye, A. O. Arowojolu, O. B. Shittu, and J. I. Anetor, "Cadmium toxicity: a possible cause of male infertility in Nigeria," Reproductive Biology, vol. 6, no. 1, pp. 17-30, 2006.

[24] A. W. Obianime and J. S. Aprioku, "Comparative study of artesunate, ACTs and their combinants on the hormonal parameters of the male guinea pig," Nigerian Journal of Physiological Sciences, vol. 24, no. 2, pp. 101-106, 2009. 
[25] D. W. Nicholson, "From bench to clinic with apoptosis-based therapeutic agents," Nature, vol. 407 , no. 6805 , pp. $810-816$, 2000.

[26] N. Choudhury, A. S. Truswell, and Y. McNeil, "Comparison of plasma lipids and vitamin $\mathrm{E}$ in young and middle-aged subjects on potato crisps fried in palmolein and highly oleic sunflower oil," Annals of Nutrition and Metabolism, vol. 41, no. 3, pp. 137148, 1997.

[27] M. Al-Azemi, F. E. Omu, E. O. Kehinde, J. T. Anim, M. A. Oriowo, and A. E. Omu, "Lithium protects against toxic effects of cadmium in the rat testes," Journal of Assisted Reproduction and Genetics, vol. 27, no. 8, pp. 469-476, 2010.

[28] G. Labbe, D. Pessayre, and B. Fromenty, "Drug-induced liver injury through mitochondrial dysfunction: mechanisms and detection during preclinical safety studies," Fundamental and Clinical Pharmacology, vol. 22, no. 4, pp. 335-353, 2008.

[29] S. J. S. Flora, M. Mittal, and A. Mehta, "Heavy metal induced oxidative stress and its possible reversal by chelation therapy," Indian Journal of Medical Research, vol. 128, no. 4, pp. 501-523, 2008.

[30] N. H. P. Cnubben, I. M. C. M. Rietjens, H. Wortelboer, J. van Zanden, and P. J. van Bladeren, "The interplay of glutathionerelated processes in antioxidant defense," Environmental Toxicology and Pharmacology, vol. 10, no. 4, pp. 141-152, 2001.

[31] S. K. Sandur, H. Ichikawa, M. K. Pandey et al., "Role of prooxidants and antioxidants in the anti-inflammatory and apoptotic effects of curcumin (diferuloylmethane)," Free Radical Biology and Medicine, vol. 43, no. 4, pp. 568-580, 2007. 


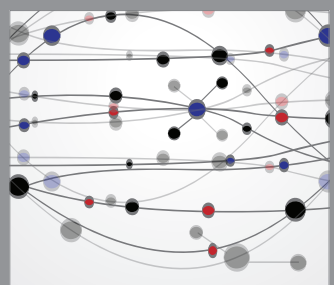

The Scientific World Journal
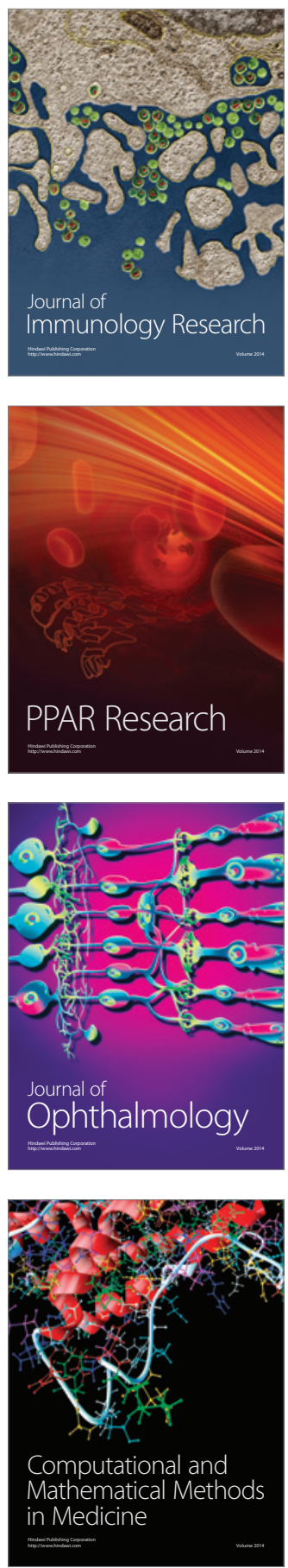

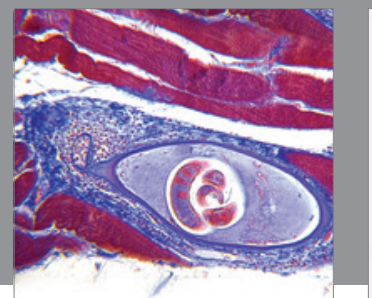

Gastroenterology

Research and Practice
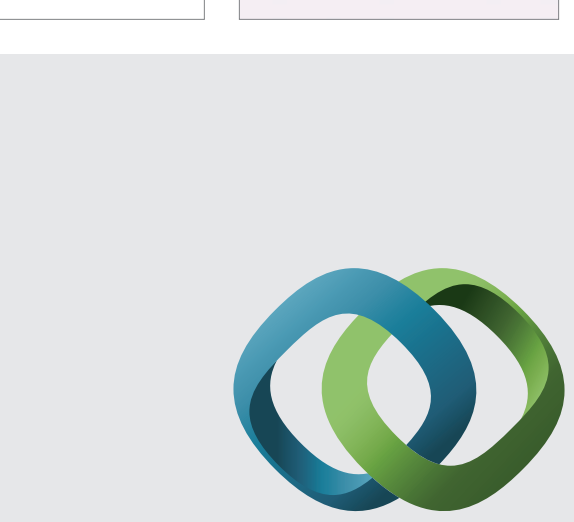

\section{Hindawi}

Submit your manuscripts at

http://www.hindawi.com
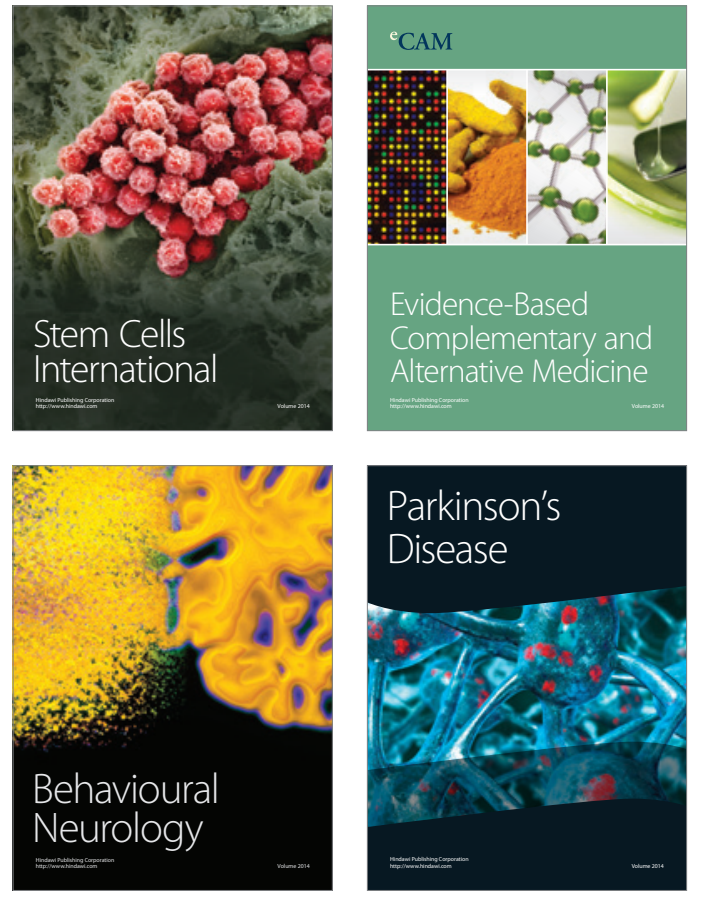
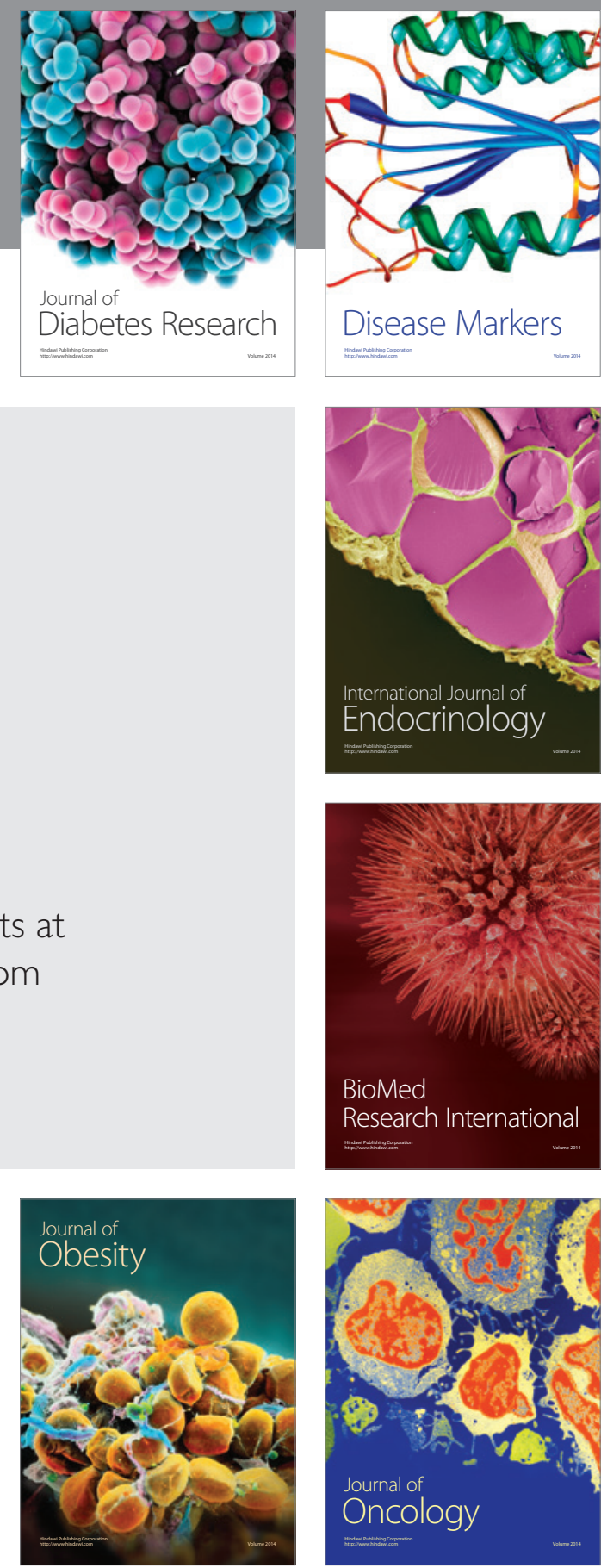

Disease Markers
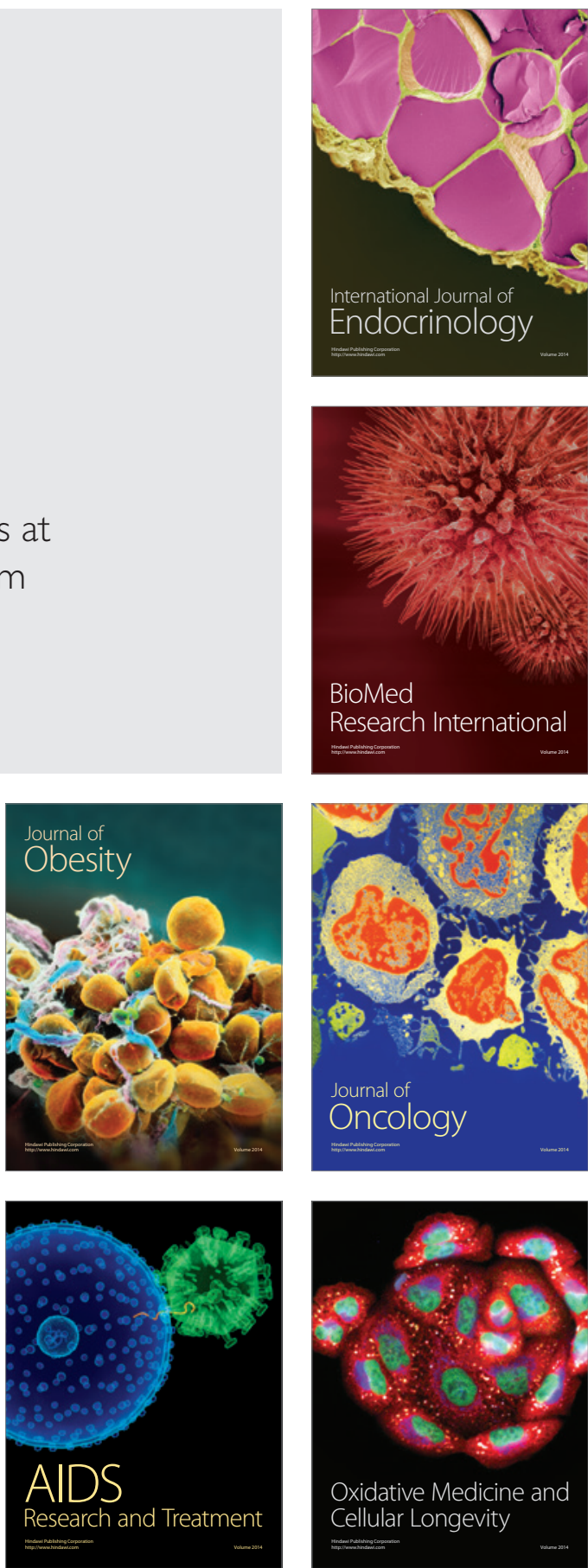